\title{
LA APORTACIÓN DEL SISTEMA URBANO A LA GOBERNABILIDAD DEL REINO DE CASTILLA DURANTE LA ÉPOCA DE LOS REYES CATÓLICOS $(1474-1504)^{1}$
}

\author{
THE URBAN CONTRIBUTION \\ TO THE GOVERNMENT OF CASTILE \\ DURING THE CATHOLIC MONARCHS' PERIOD \\ (1474-1504)
}

\author{
MARÍA ASENJo GONZÁLEZ \\ Universidad Complutense de Madrid
}

\begin{abstract}
Resumen: La aportación de las ciudades a la gobernabilidad del reino en el reinado de los Reyes Católicos ha estado condicionada por la perspectiva historiográfica que ponía el énfasis en el autoritarismo político de la monarquía que rivaliza con la nobleza por su control. En el presente trabajo proponemos un análisis del papel de las ciudades de realengo gestoras de amplios territorios. Su aportación sería decisiva en el giro político dado en el reinado, volcado en una política exterior ambiciosa y soportada por una administración eficaz. En ese reinado se establece una colaboración política con las ciudades que recupera la importancia del acuerdo y el apoyo interesado. Desde esa perspectiva se evalúan las acciones de los diferentes poderes y el papel de la monarquía, que llegaría a contemplar la relación rey-súbditos como base del gobierno del reino.
\end{abstract}

Palabras clave: Ciudades; Política; Reyes Católicos; Sociedad; Economía; Monarquía; Relaciones de poder; Castilla; Baja Edad Media; Oligarquía urbana.

\begin{abstract}
The historical analysis of urban governs' contribution in Castile of Catholic Monarchs (1474-1504) has been conditioned by historiography that paid attention on the royal authority and the fight between king and lords to control the Kingdom power during the Trastamara's period (1369-1504). This paper tries to study the participation of the realengo cities. This cities governed large territories with jurisdictional power. Cities gave support for the political change of the Kingdom interested in an ambitious foreign policy that needed a good administration. During this reign a political collaboration was established with the cities, this recovered the importance of the agreement and alliance. From this point of view this paper evaluates the actions of the different Kingdom powers and the role of the Monarchy. It also looks at the King-subject relationship as the base of Kingdom government.
\end{abstract}

Keywords: Cities; Towns; Politics; Society; Economy; Kingship; Catholic Monarchs; Rulers; Castile; Later Middle Ages; Urban Oligarchic power.

${ }^{1}$ El presente trabajo recoge algunos resultados obtenidos en el transcurso del proyecto de investigación "Las relaciones de conflicto en sus prácticas representativas (La Corona de Castilla en su contexto europeo, siglos XIII-XV)" (Ref. HUM2006-05233), dirigido por José Manuel Nieto Soria; y el proyecto relativo a "Espacio político y demarcaciones socioeconómicas. Redes urbanas de villas y ciudades en la Castilla sudoriental (1450-1520)" (HUM2007-61076), dirigido por la autora. Ambos desde la Universidad Complutense de Madrid y financiados por el Ministerio de Educación y Ciencia. 


\section{SUMARIO}

Introducción.- 1. Situación de la monarquía al inicio del reinado: a) Buenas condiciones de la economía del reino. b) Panorama político intermacional y recursos fiscales. c) Poder militar y creación de un ejército permanente.- 2. Panorama de las ciudades castellanas de realengo a fines del siglo XV.- 3. Las ocasiones de plasmación de la colaboración: relaciones de pacto o servicio.- 4. Conflictos y desencuentros.- Conclusión.

\section{INTRODUCCIÓN}

El análisis de la aportación del sistema urbano a la gobernabilidad del reino en el reinado de los Reyes Católicos parece condicionado por algunas posiciones historiográficas que determinan de partida dicha valoración, al situarla en la trayectoria de los reinados trastámaras, en la que el juego político se presentaba en clave de creciente autoritarismo monárquico que rivaliza con la alta nobleza para afianzar su poder ${ }^{2}$. Ciertamente este reinado constituye un período con características propias y, aunque mantiene pautas de continuidad con el período anterior, también se producen cambios trascendentales en el tratamiento político que tendrán consecuencias en la posterior historia de España. En cualquier caso, conviene recordar que todavía a fines del siglo XV la Corona de Castilla era una monarquía de base estamental, en la que la representación del "tercer estado" en las Cortes del Reino había quedado reducida a diecisiete ciudades de realengo, a las que sólo se incorporaría Granada en 1492. En ese marco socio-político, los Reyes Católicos procedieron a incrementar las atribuciones y competencias de gobierno a las villas de realengo, que junto a lugares de señorío articulaban el territorio y posibilitaban la gestión a escala de todo el reino. En esa realidad, parece indiscutible el protagonismo de los núcleos urbanos de todo el reino, que mantenían una dimensión política de representación y gestionaban su gobierno, en el marco de lo que se ha denominado "el señorío colectivo urbano"3.

${ }^{2}$ La obra de L. SuÁreZ FERnÁndeZ, Nobleza y monarquía. Puntos de vista sobre la historia castellana del siglo XV, Valladolid, Univ. de Valladolid, 1975, supuso un hito y un punto de partida en los trabajos de historia política del período que condicionó interpretaciones posteriores. Sobre el poder regio y su naturaleza J.M. NIETO SORIA, El "poderío real absoluto" de Olmedo (1445) a Ocaña (1469): La monarquía como conflicto, "En la España Meedieval”, 21 (1998), pp. 159-228. La expresión "poderío real absoluto" la entiende como "reflejo de la preeminencia y soberanía regias y por lo tanto un recurso imprescindible, teniendo en cuenta las características jurídico políticas de la época. Pero era tambien un instrumento al servicio de los intereses de los más influyentes ya que era decisivo para garantizar la seguridad jurídica del poder real y la preeminencia política de los más influyentes" (p. 227).

${ }^{3}$ L. SUÁREZ FERNÁNDEZ, Reflexión sobre las Cortes medievales castellano-leonesas en homenaje a Juan Torres Fontes, Homenaje al profesor Juan Torres Fontes, 2 (1987), pp. 16451656. Este autor asegura que los Trastámara integraron a las Cortes es su sistema de Estado de predominio nobiliario y agudizaron el carácter de "señorío colectivo" de las ciudades. M.A. LADERO QUESADA, Castilla a comienzos del siglo XVI, en La hora de Cisneros, ed. J. PEREZ, Madrid, U.C.M., 1995, pp.35-42. Sobre el peso de la urbanización en Castilla: B. YUN CASALILLA, Entre la economía mundo y el crecimiento polinuclear (los rasgos generales de la economía europea en el tránsito del siglo XVI, 1490-1530), en De la unión de Coronas al Imperio de Carlos V. Barcelona, 21-25 de febrero de 2000. Congreso Internacional, ed. E. BELEGUER 
Somos conscientes de que aceptar la dimensión política de la participación urbana en la gobernabilidad del reino implica lograr, en primer lugar, vencer esos lastres historiográficos que condicionan o limitan esa participación y hacen difícil el posicionamiento sobre determinados problemas históricos planteados sobre la interdependencia de los sistemas de gobierno y en clave de relaciones de poder ${ }^{4}$. Para ello es preciso reconocer un papel político diferenciado que se otorga a las ciudades de realengo a escala del reino. Lo cual parece razonable si tenemos en cuenta sus competencias y capacidad de autogobierno en el marco de la sociedad estamental. Sin cometer el error de insistir en que la coerción es el rasgo distintivo del poder, típico de la historia institucional, como denuncia Foucault, y de ignorar los mecanismos de obediencia, situados también en el ámbito de lo político, que funcionan sin violencia y no por la prohibición ${ }^{5}$. El otro impedimento historiográfico se deduce del protagonismo otorgado al que se considera el debate fundamental que se entabló sobre la dualidad nobleza/monarquía, o bien porque no se reconoce capacidad propia de acción política a las ciudades ya que se mantiene que ellas constituyen parte de la monarquía. Una última limitación se sitúa en la dimensión autoritaria del poder monárquico lo cual supone una percepción de autoridad omnímoda, que se presenta como imposible de compartir con otras formas de poder coetáneo y, en caso de aceptar la compartimentación, siempre se le otorga una superioridad y primacía que convierte a los otros poderes en comparsa de sus opciones de gobierno. Por último, habría que reflexionar sobre el carácter pactual de muchos de los avances políticos del período, tan aceptado en el marco de relaciones y valores feudales que se habían difundido con gran facilidad en los reinos peninsulares bajomedievales ${ }^{6}$.

No hay duda de que esas posiciones historiográficas limitan la percepción de una realidad política, que resultaba mucho más compleja de lo

CEBRİ̀, Madrid, Fundación estatal para las conmemoraciones de los Centenarios de Felipe II y Carlos V, 2001, pp. 29-45, véase p. 38 y ss.

${ }^{4}$ Algunas reflexiones para el período bajomedieval en nuestro trabajo: El Estado y la distribución del poder, en El Marqués de Santillana (1398-1458). Los albores de la España Moderna. El hombre de Estado, Madrid, Nerea, 200, pp. 37-83 y M. ASENJO GONZALEZ, El poder regio y las ciudades castellanas a mediados del siglo xv. Pragmáticas, ordenamientos y reuniones de Cortes en el reinado de Juan II, en Os Reinos Ibéricos na Idade Media.Homenaje al Profesor H. Baquero Moreno, eds. L. ADÃO DA FONSECA; L.C. AMARAL; M.F. FERREIRA SANTOS, Lisboa, Livraria Civilisação Editora, 2003, pp. 947-955. Desde otra perspectiva se adentra: C. SILIO CORTÉS, Isabel la Católica. Fundadora de España. Su vida. Su tiempo. Su reinado (1451-1504), Madrid, Espasa Calpe, 1954.

${ }^{5}$ Tal y como señala: A.M. HeSPANHA, Vísperas de Leviathan. Instituciones y poder político (Portugál, siglo XVII), Madrid, Taurus, 1989, p. 33. Reflexiones en el mismo sentido de P. FERNANDEZ AlBADALEJO, Fragmentos de monarquia, Madrid, Alianza, 1992 y B. CLAVERO ARÉVALO Tantas personas como estados. Por una antropología política de la historia europea. Madrid, Tecnos, 1986.

${ }^{6} \mathrm{El}$ marco político territorial y jurisdiccionalmente fraccionado en que se constituía la Castilla bajomedieval se articulaba en clave feudal, sobre pactos de acuerdo y sometimiento al rey, que se evidenciaban en las reuniones de Cortes, y que se imbricaban en el lenguaje feudal dominante. La lenta aparición de un poder autoritario por parte de la monarquía feudal potenciaría nuevas formas de integración a escala de obediencia de "súbdito", que estimularían nuevos comportamientos de unidad política basados en la religión y la lengua: R. BARLETT, Patterns of Unity and Diversity in medieval Europe, en The Birth of Identities. Denmark and Europe in the Middle Ages, ed. B.P. MCGUIRE, Copenhague, Reitzel, 1996, pp. 29-45. 
que a primera vista pudiera parecer, a partir del reduccionismo de una visión "estatal" prematura para la época. El predominio ideológico de prototipos y códigos emanados de un feudalismo tardío, en el que la privanza y el servicio se dibujan como vehículo de comunicación para las partes, refleja mucho mejor las pautas de relación entre monarquía y ciudades en la Castilla del siglo $\mathrm{XV}^{7}$. Desde esta nueva óptica, ciertamente, se atenúa también la prepotencia monárquica que pasa a ser percibida como un poder en construcción, necesitado de apoyos políticos y soporte social, aportaciones que al inicio de éste reinado se hacían más imprescindibles ${ }^{8}$.

Desde estas nuevas perspectivas de análisis se pueden conocer diferentes facetas de acción de las formas de poder que actúan en el reino y, en consecuencia, medir el alcance del poder monárquico en su capacidad de gobierno $\mathrm{y}$, en particular, con relación a las ciudades. En este sentido, conviene recordar que las ciudades de realengo se encontraban vinculadas a la jurisdicción regia y constituían un referente fundamental en la puesta a punto del sistema fiscal regio, la creación de un ejército permanente y la ampliación de las competencias de justicia y legislación de los reyes. De ese modo, se comprende que hubiera necesidad de acuerdo político que interesaba a las partes y que proporcionaba ventajas a la oligarquía, al tiempo que exigiría adaptaciones y renuncias en sus respectivos objetivos y ambiciones.

\section{SituACIÓN DE LA MONARQUÍA AL INICIO DEL REINADO}

El punto de arranque de nuestra reflexión requiere precisar las condiciones de la política en el período estudiado a fin de percibir en qué medida la monarquía podía requerir el apoyo de otras instancias de poder para facilitar la gobernabilidad del reino. Para ello haremos un seguimiento de algunos de los asuntos fundamentales en los que las ciudades podían realizar su aportación.

${ }^{7}$ M. ASENıO GoNZÁlez, Ciudades y poder político en la Castilla Trastámara (1400-1450), en Coups d'Etat à la fin du Moyen Age? Aux fondements du pouvoir politique en Europe Occidentale, eds. F. ForONDA, F. GENET y J.M. NIETO SORIA, Madrid, Casa de Velázquez, 2005, pp. 365-401.

${ }^{8} \mathrm{La}$ renovación los puntos de vista y análisis para comprender las luchas políticas de los reinados de la dinastía Trastámara la realizó L. SUÁREZ FERNÁNDEZ, Nobleza y monarquía. Puntos de vista sobre la historia castellana del siglo XV, Valladolid, Univ. de Valladolid, 1975, pero esa perspectiva dual del trabajo condicionó otras posibilidades e interpretaciones. En cuanto a la vision de las ciudades embebidas en la monarquía, la idea se encuentra soportada en los trabajos de perspectiva institucional que entienden que la trayectoria política de los concejos se encontraba fuertemente intervenida desde 1345, con la instauración del regimiento. Situación que se fue afirmando hasta llegar a un sometimiento al poder regio en el reinado de los reyes Católicos: A.M. MOYA, El estado absoluto de los Reyes Católicos. "Hispania. Revista española de historia", 35/129 (1975), pp 75-119 y R. POLO MARTín, Los Reyes Católicos y la insaculación en Castilla, "Studia Historica. Historia Medieval", 17 (1999), pp. 137-197. 


\section{a) Buenas condiciones de la economía en el reino}

El crecimiento económico de la segunda mitad del siglo XV tuvo un punto de arranque agropecuario que se considera consecuencia de la mejora de la relación entre población, territorio y formas de subsidencia ${ }^{9}$. La tendencia creciente a que las rentas se pagasen en moneda supuso un alivio para los campesinos que pudieron colocar buena parte de su producción en el mercado y también se llevó a cabo una eficiente explotación de los recursos al mejorar las técnicas y adaptar los cultivos a las necesidades de los mercados. Castilla mostraba así una actividad productiva en éste período que desmonta algunas ideas estereotipadas de su función exportadora de materias primas, como supuesta periferia proveedora de las mismas y simple puente de paso para los metales preciosos de las Indias. En esta economía interior en crecimiento, conviene recordar que la demanda estuvo estimulada desde las ciudades y en algunos casos dio lugar a la aparición de una agricultura intensiva y altamente especializada ${ }^{10}$. El comercio que animaba toda esta actividad se desplegaba con éxito en torno a dos áreas privilegiadas: la de Andalucía que tenía a Sevilla y su región como referente, completada con las ciudades de su entorno como Cádiz, Jerez y el Puerto de Santa María, donde la actividad comercial se animaba con la pesca y las incursiones en las costas africanas. En éste área, desde los puertos de Huelva: Palos, Moguer y Lepe, y las acciones que se emprendían desde las Islas Canarias. Un espacio en el que Sevilla brillaba con luz propia, actuando como gran plaza mercantil y sede bancaria de diferentes operaciones y con gran radio de acción, y ciudad a la que acudían mercaderes extranjeros y particularmente italianos. La otra área de actividad se sitúa en el norte: Burgos y la zona del Cantábrico, donde se concentra la exportación de lana que había animado los intercambios mercantiles en centurias anteriores. Un ámbito menos moderno que el andaluz

${ }^{9}$ M.A. LADERO QUESADA, El crecimiento económico de la Corona de Castilla en el siglo XV: ejemplos andaluces, "Medievalia" (1992), pp. 217-35, Este autor asegura que "Castilla vivió en el siglo XV una época de gran expansión que le permitió actuar como adelantada y pionera de Europa entera y la salida a la crisis de 1462 le fue mucho más favorable que en otros países hispánicos". Desde 1480 los reyes se permitieron una política enérgica y, arriesgada y en el último decenio del siglo xv se reanudó el movimiento expansivo de la economía castellana, p. 218. Ver también: E. AZNAR VALLEJO, Productos, mercados atlánticos en el desarrollo económico andaluz del siglo X $V$, en Prodotti e techniche d'oltremare nelle economie europee. Secc. XIII-XVIII, Atti della XXIX Settimana di Studi a Prato, ed S. CAVACIOCHI, Prato, Florencia, 1998, pp. 439-449.

${ }^{10} \mathrm{~B}$. YUN CASALILLA, Economic cycles and structural changes, en Handbook of European History 1400-1600. Late Middles Ages, Renaissance and Reformation., eds. T.A. BRADY; H.A. OBERMAN; J.D. TRACY, Leiden, E.J. Brill, 1994, pp. 113-146; B. CAUNEDO DEL POTRO, Reflexiones en torno al comercio exterior castellano en las postrimerias de la Edad Media, en La Península Ibérica en la Era de los Descubrimentos (1391-1492). Actas III Jornadas HispanoPortuguesas de Historia Medieval, ed. M. GONZÁLEZ JIMÉNEZ, Sevilla, Junta de Andalucía. Consejería de Cultura, 1997, pp. 393-420. 
pero que recuperaba actividad al calor de la estabilidad política y el despegue económico del Atlántico norte ${ }^{11}$.

A otra escala, el comercio interior jugó un papel fundamental en la distribución de productos tanto de importación como de producción interna. La red de comunicaciones terrestres, transitada por carreteros y muleros, canalizaba este comercio local que tuvo una gran importancia en el despegue económico del reino ${ }^{12}$.

La actitud de la política monarquía en las cuestiones de intercambios mercantiles se decantaba hacia posiciones de apertura manifestadas en la reducción de trabas fiscales de aduanas y la consiguiente aparición de ventajas para los intercambios de todo tipo de mercancías que no estuvieran vedadas o prohibidas, tal y como ocurría con la moneda ${ }^{13}$. Pero incluso en este asunto la fuerza de los intercambios hacía muy difícil el seguimiento y castigo de los que traficaban ilegalmente con moneda de oro castellana ${ }^{14}$.

Al mismo tiempo la política regia en materia mercantil parecía condicionada por las teorías "bullionistas" que, obsesionados por la salida de los metales preciosos del reino y por mantener las reservas de oro, preconizaban soluciones tendentes a invertir la balanza de pagos en los intercambios internacionales. Se preocuparon por la estabilidad de la moneda ajustando el valor del maravedí (moneda de cuenta) a la moneda de oro. Por lo que se refiere a la práctica económica, se habían generalizado las técnicas de financiación y el uso de las letras de cambio.

\section{b) Panorama político internacional y recursos fiscales}

Sobre el panorama político internacional, es sabido que se convertiría en la piedra angular de las decisiones monárquicas, en particular tras el fin de

${ }^{11} \mathrm{D}$. IGUAL LUIS, La difusión de productos en el Mediterráneo y en Europa occidental en el tránsito de la Edad'Media a la Europa Moderna, en Fiere e mercati nella integrazione delle economie europee. Secc. XIII-XVIII. XXXII Settimana di Studi (8-12 mayo 2000), ed. S. CAVACIOCCHI, Prato /Firenze, 2001, pp. 453-494.P. IRADIEL MURUGARREN, De la crisis medieval al Renacimiento (siglos XIV y XV), en Historia de España, ed. A. DOMÍNGUEZ ORTIZ, vol. IV, pp. 9-296. Barcelona, 1989.

${ }^{12} \mathrm{~A}$. MACKAY, Comercio/mercado interior y la expansión económica del siglo $X V$, en Actas del II Coloquio de historia medieval andaluza: hacienda y comercio (Sevilla 8-10 de abril de 1981), Sevilla, Exma. Dip. Prov. de Sevilla, 1982, pp. 103-123; H. CASADO ALONSO, Crecimiento economico y redes de comercio interior en la Castilla septentrional (siglos XV y XVI) en Imágenes de la diversidad. El mundo urbano en la Corona de Castilla (siglos XVI$X V I I I)$, ed. J.I. Fortea Pérez, Santander, Universidad de Cantabria, 1997, pp. 283-322; M. ASENJO GONZALEZ, El comercio. Actividad económica y dinámica social en las plazas y mercados de Castilla. Siglos XIII-XV, en Plazas y mercados medievales. 8 a Jornadas del CEMYR. Universidad de La Laguna (Tenerife) 9-11 de mayo 2001, Tenerife, 2002, pp. 97-134

${ }^{13}$ J.M. SANCHEZ BENITO, La Corona de Castilla y el comercio exterior. Estudio del intervencionismo monárquico sobre los tráficos mercantiles en la Baja Edad Media, Madrid, Editorial Ciencia, 1993; J.M. BELLO LEON, Extranjeros en Castilla (1474-1501). Notas y documentos para el estudio de su presencia en el reino a fines del siglo XV, La Laguna, Centro de Estudios Medievales y Renacentistas de la Laguna, 1994.

${ }^{14}$ Sobre esta cuestión consultar el trabajo de M.A. LADERO QUESADA, El Banco de Valencia, los genoveses y la saca de moneda de oro castellana. 1500-1503, "Anuario de Astudios Medievales", 17 (1987), pp. 571-594. 
la guerra de Granada en 1492. Esa trayectoria que buscaba hacer de la nueva Corona una potencia internacional con ambiciones políticas en Mediterráneo y el Atlántico necesitaba del sosiego interno y de algunos cambios fundamentales en política social y económica ${ }^{15}$. No olvidemos que Castilla partía de una larga guerra civil (1476) que no se resolvería hasta 1480 y desde 1482 se iniciaban los preámbulos de la guerra de Granada ${ }^{16}$. Los problemas inmediatos del reino se solucionaron en 1479 con el final de la guerra (1475-1479) y cuando ese mismo año 1479 moría Juan ii de Aragón y heredaba el reino su hijo Fernando ii, nacía una nueva monarquía dispuesta a poner en equilibrio los deseos de unidad y el respeto a la pluralidad que había caracterizado ya a la Corona de Aragón ${ }^{17}$.

Abordar tales proyectos suponía la necesidad de disponer de saneados recursos para abordar las empresas de conquista y de expansión: Granada, Italia y América. Para ello recuperaron las rentas de la Corona, que se encontraban abandonadas o mal recaudadas ${ }^{18}$. Todo ello, sin afectar al sistema señorial y urbano que les prestaba su apoyo y que seguiría siendo clave para asegurar el control del territorio y el gobierno del reino ${ }^{19}$. Pero lo cierto es que las medidas económicas, que se establecieron en las Cortes de Toledo de 1480 , tenían el propósito de recuperar las rentas de la realeza, entregadas como juros en el reinado de Enrique iv, y ello iba a despertar cierta desconfianza en algunos sectores, al tiempo que una satisfacción generalizada a escala popular, lo cual ofrecería también oportunas ventajas propagandísti$\operatorname{cas}^{20}$.

${ }^{15}$ Sobre el desarrollo del reinado sigue siendo un libro de referencia la obra de D. Clemencín, Elogio de la Reina Católica Doña Isabel, Madrid, 1821 y con posterioridad la de T. DE AZCONA, Isabel la Católica. Estudio crítico de su vida y su reinado, Madrid, BAC, 1993.

${ }^{16}$ M.A. LADERO QUESADA, Milicia y economía en la guerra de Granada. Valladolid, Univ. de Valladolid, 1964. Coordinado por este mismo autor: La incorporación de Granada a la Corona de Castilla. Actas del Symposium conmemorativo del quinto centenario (Granada, 2 al 5 de diciembre 1991), Granada, Comares, 1993.

${ }^{17}$ L. SUÁREZ FERNÁNDEZ, Los Trastámara y los Reyes Católicos. Historia de España. 7. Madrid, Gredos, 1985, p. 237; M.A. LADEROQUESADA, Fernando ii de Aragón, el Rey Católico: el Estado, en Fernando II de Aragón, el Rey Católico, ed. M.A. LADERO QUESADA, Zaragoza, Institución Fernando el Católico, 1995. pp. 11-27.

${ }^{18}$ ÍDEM, La Hacienda Real de Castilla en el siglo XV, La Laguna, Public de la Univ., 1973.

${ }^{19} \mathrm{P}$. IRADIEL, Señoríos jurisdiccionales y poderes públicos a finales de la Edad Media, en Poderes públicos en la Europa Medieval: Principados, Reinos y Coronas. Actas de la XXIII Semana de Estudios Medievales de Estella (22-26 julio 1996), Pamplona, Gobierno de Navarra, 1997, pp. 69-116.

${ }^{20}$ A. MATILla TASCÓN, Declaratorias de los Reyes Católicos sobre reducción de juros y otras mercedes, Madrid, Serv. Inspec de Hacienda, 1952. El control sobre la concesión de juros, según los datos de este autor y de Clemencín se deduce: que la Iglesia resultó particularmente favorecida. Si bien los altos dignatarios sufrieron reducciones. Las Ordenes Militares fueron las que sufrieron una mayor reducción y las oligarquías urbanas de los concejos fueron tratadas con gran rigor, ya que perdieron casi la totalidad de juros y la mitad de las mercedes. La nobleza, por su parte, sufrió la reducción en la mitad pero se quedó en un 25-40\%, consolidando las mercedes anteriores a 1464: J. CARRETERO ZAMORA Cortes, monarquía, ciudades. Las Cortes de Castilla a comienzos de la época moderna (1475-1515), Madrid, Ed. Siglo XXI, 1988, p. 160; S. HALIÇZER The Castilian Aristocracy and the Mercedes Reform of 1478-1482,"The Hispanic American Historical Review“",55 (1975), pp. 449-467. Considera que la reducción pretendió dos cosas: determinar los justos títulos de las mercedes e incrementar los recursos propios de la Corona. 
Se comprende que en estos cometidos la fiscalidad jugase un papel primordial al proporcionar los recursos necesarios para abordar tan ambiciosos fines. La fiscalidad regia se soportaba en la percepción de ingresos ordinarios, que se complementaba con la entrada de los extraordinarios, como los servicios aprobados en Cortes $^{21}$. Se comprende que, en esas circunstancias, las ciudades pasaran a tener un destacado papel al ser sus oligarquías las garantes de la situación de concordia y de validez del procedimiento recaudatorio que sustentaba la hacienda regia, al mismo tiempo que también eran un sector privilegiado al participar en el arrendamiento y beneficiarse de la compra de juros sobre las rentas de la monarquía, situados en las alcabalas y tercias reales ${ }^{22}$. Pero lo cierto es que esas rentas se recaudaban con mayores garantías desde la generalización del sistema de "encabezamiento", ya que se cobraron por medio de igualas que pagaban como impuesto directo, y sus beneficios se distribuían entre los miembros de las clases dominantes de villas y ciudades que hubiesen adquirido u obtenido los juros ${ }^{23}$. Las innovaciones en las formas de recaudación por medio de encabezamientos, dejaban en manos del los poderes locales la responsabilidad de percibir y redistribuir lo recaudado, de acuerdo con los pagos de rentas comprometidos en los juros. En cuanto a los servicios de Cortes, estas percepciones sí se recaudaron como impuestos propiamente regios y contribuyeron de un modo directo a soportar los gastos de la monarquía, junto a otras rentas de importancia que se encontraban bien saneadas, como las de las Órdenes militares.

\section{c) Poder militar y creación de un ejército permanente}

En cuanto al propósito de iniciar la creación de un ejército profesional y permanente era una preocupación común a los monarcas de su tiempo ${ }^{24}$. Desde 1486, cuando los Reyes confirmaron la Hermandad se le otorgaron las leyes que se había dado a si misma. De ese modo, se abandonaba la ficción de que se trataba de una construcción temporal para convertirla en una opción de cuerpo armado permanente con hombres de infantería y caballería. Pero las quejas por el empleo de la Hermandad fuera del reino hicieron que en 1498 se rectificara para devolver la jurisdicción a los alcaldes y cuadrilleros. No

${ }^{21}$ J.M. CARRETERO ZAMORA, Los servicios de Cortes y las necesidades financieras de la monarquía, "Cuadernos de Historia Moderna", 8 (1987), pp. 31-56.

${ }^{22}$ La opción de adquirir juros se prueba como la fuente de renta más apetecida a comienzos del siglo XVI: J. AGUADO DE LOS REYES, Los capitales sevillanos en la época de Carlos V, en El emperador Carlos v y su tiempo. Actas de las ix Jornadas de Historia Militar, 24-28 marzo 1999. Sevilla, ed.: Cátedra.General Castaños, Madrid, 2000, pp. 489-506; M. ASENJO GONZÁLEZ, Encabezamientos de alcabalas en Segovia y su episcopalíá (1495-1506)'. Innovaciones y reacción social, "En la España Medieval”, 20 (1997), pp. 251-280.

${ }^{23}$ ÍDEM, Los encabezamientos de alcabalas en la castilla bajomedieval. Fuentes de renta y política fiscal, en Fiscalidad de Estado y fiscalidad municipal en los reinos hispánicos medievales, eds. D. MENJot; M. SÁnCHEZ, Madrid, Casa de Velázquez, 2006, pp. 135-170.

${ }^{24}$ M.A. LADERO QUESADA, Les finances royales de Castille à la veille des temps modernes, "Annales. Economies Sociétés Civilisations", 3 (1970), pp.775-788 y W.M. ORMROD, Les monarchies d'Europe occidentale à la fin du Moyen Age, en Systèmes économiques et finances publiques, ed. M. BONNEY, París, PUF, 1996. 
obstante, de ahí saldría el germen del futuro ejército del rey de la edad moderna $^{25}$. Prueba de que el asunto estaba en mente de los monarcas es que ya en 1492 Alonso de Quintanilla hacía una valoración, asociada al cálculo de población general, que tenía como propósito dotar a la monarquía de un ejército permanente en el que los espingarderos pasasen a ser la fuerza principal, sustituyendo en protagonismo a los ballesteros. El 22 de febrero de 1496 se daba noticia a Segovia del acuerdo tomado en la Junta de la Hermandad, reunida en Santa María del Campo en 1495, para que se llevara adelante una propuesta que se concretaba a las ciudades y villas de los reinos en que deberían organizar una infantería de hombres armados, eligiendo de entre doce hombres a uno, a fin de que fuesen los varones más hábiles y suficientes, de entre veinte y cuarenta años. A los elegidos se les proporcionarían las armas necesarias, que correrían a cargo de los otros once, y a todos se encargaba tomar bajo su cuenta las responsabilidades y competencias que le permitiesen acudir al servicio de armas al ser llamado por causa de guerra. Las cuentas del tesorero Alonso de Morales entre 1495 y 1503 dejan bien claro, en el apartado de salidas, que el dinero castellano se volatilizaba en la guerra, ya fuese para luchar en Nápoles o en las expediciones mediterráneas contra el turco ${ }^{26}$.

Por último, cabe señalar la colaboración de las ciudades en el propósito de reforzar la acción legislativa y judicial del poder regio ${ }^{27}$. En este sentido, las figuras del juez de residencia, el gobernador y el asistente se pueden considerar los precedentes del corregidor, si bien el primero es más un juez, el segundo tiene una naturaleza más militar y el tercero es un interventor en el plano normativo. Las Cortes de 1480 dieron el giro hacia la consolidación de la figura del corregidor castellano moderno, en las ciudades $\mathrm{y}$ villas del reino ${ }^{28}$.

\section{PANORAMA DE LAS CIUDADES CASTELlANAS DE REALENGO A FINES DEL SIGLO XV}

Hay que destacar la favorable disposición de las ciudades ante los nuevos retos planteados por un poder monárquico ambicioso en sus propósitos y comprometido con unos valores políticos nuevos. En un complejo contexto de crisis de legitimidad la monarquía de Isabel desarrollaría un sobreesfuerzo

\footnotetext{
${ }^{25}$ M.A. LADERO QUESADA, La organización militar de la corona de Castilla en la Baja Edad Media, en Castillos medievales del reino de León, Madrid, 1989, pp. 11-34 y R QUATREFAGES, A la naissance de l'armée moderne, "Melanges de Casa de Velázquez", 13 (1977), pp. 119-159.

${ }^{26}$ Conservado en AGS. (Archivo General de Simancas), Contaduría Mayor, $1^{\text {a }}$ Época, leg.. 98. Véase T. de AZCONA, Isabel la Católica, op. cit., pp. 903-904.

${ }^{27}$ S.DE DIOS, Instituciones centrales de gobierno, en Isabel la Católica y la política, ed. J. VALDEÓN BARUQUE, Valladolid, Ambito. Instituto de Historia Simancas, 2001, pp. 217-257.

${ }^{28}$ M. LUNEFELD, Los corregidores de Isabel la Católica, Barcelona, Labor, 1989. J.M. CARRETERO ZAMORA, Cortes, monarquía, ciudades. Las Cortes de Castilla a comienzos de la época moderna (1475-1515), Madrid, siglo XXI, 1988, p. 168.
} 
de formulación de principios ideológicos justificadores a la vez que un amplio despliegue propagandístico ${ }^{29}$. Las opciones de respuesta por parte de los poderes territoriales se vieron mejoradas por las favorables condiciones en las que se vivieron aquellos años ${ }^{30}$.

Así, un crecimiento demográfico sostenido y una actividad económica pujante acompañaron los últimos decenios del siglo XV y los primeros años del XVI ${ }^{31}$. Aspecto que se relaciona con los parámetros de crecimiento general para todo el reino y en los que los sistemas urbanos actuarían en clave de núcleos dinamizadores de algunos de los procesos de producción y transformación de mercancías y productos. La importancia que tenían los asuntos económicos en las decisiones de los concejos castellanos queda probada por el énfasis con el que se encuentran abordados en las ordenanzas concejiles, en las que figuran en unas proporciones cercanas a más del sesenta por ciento de sus contenidos ${ }^{32}$. Recordemos que las competencias relativas a la organización del mercado, la gestión del avituallamiento y control de calidades, pesos y medidas otorgaban a los poderes urbanos capacidad para gestionar asuntos de índole económica, que por lo general se resolverían en clave de aplicación de criterios y modelos de renovación por vía de ordenanzas y leyes, que si en un principio aportaron beneficios al desarrollo artesano y mercantil, a medio plazo, acabarían esclerotizando un proceso productivo competitivo y prometedor a mayor escala y no sólo en el ámbito del reino de Castilla ${ }^{33}$.

En el ámbito social, la sociedad urbana se mostró receptiva y colaboradora en los proyectos monárquicos, siempre a tenor de las expectativas que ofrecía a los poderes oligárquicos. Esa disposición de las ciudades es un asunto fundamental que no plantea dudas ya que arrancaba de los conflictos habidos en el seno de los concejos en el curso de la centuria y en los que la monarquía había actuado como acicate en las divisiones y enfrentamientos concejiles, al incorporar a los hombres de la oligarquía de regidores como miembros del Consejo Real, cuyas competencias en esos momentos eran las

${ }^{29}$ J.M. NIETO SORIA, Los fundamentos ideológicos del poder regio, en Isabel la Católica y la política, op . cit. . pp. 181-216, p. 189. A juicio de éste autor, esos principio giraron en torno a la teologización del poder, el historicismo político, el mesianismo milenarista, el nacionalismo patriótico y la reformación del reino.

${ }^{30} \mathrm{~A}$. COLlantes DE TERÁN, Las ciudades de Andalucía, en La città del Mediterraneo all'Apogeo dello sviluppo medievale: aspetti economici e sociali. Pistoia, 1821 maggio 2001 , Pistoia, Centro italiani di studi di storia e d'arte, 2003, pp. 447-484.

${ }^{31}$ M. ASENJo GonzÁlez, Demografía. El factor humano en las ciudades castellanas y portuguesas a fines de la Edad Media en Las sociedades urbanas en la España Medieval. XXIX Semana de Estudios Medievales. Estella 15-19 julio 2002, Pamplona, Gobierno de Navarra, 2003, pp. 97-150.

${ }^{32}$ Así se comprueba en el caso de la ciudad de Toledo: M. AsENJO GONZÁLEZ, Las ordenanzas antiguas de Toledo, Siglos XIV y XV, en 'Faire bans, editz e statuz'. L'activité législative communale dans l'Occident médieval, ca. 1200-1550: sources, objets, acteurs, ed. J.M. CAUCHIES, Bruselas, Publications des Fac. Univ. de Sait Louis, 2000, pp. 85-115.

${ }^{33} \mathrm{P}$. IRADIEL, Ciudades, comercio y economía artesana, en La historia medieval en España. Un balance historiográfico (1968-1998), Pamplona, Gobierno de Navarra, 1999, pp. 603-658; M. ASENJO GONZÁLEZ, La vida económica de las ciudades de la Corona de Castilla a través dé sus ordenanzas. Siglos XIII-XVI, en Potere economici e potere politici secc. XIII-XVIII, ed. S. CAVACIOCCHI, Firenze, Le Monnier, 1999, pp. 591-605. 
cuestiones de gobernación y de gracia hasta $1459^{34}$. Se comprende que, desde esa perspectiva de participación de las ciudades en las altas instancias políticas del reino, se hiciesen propuestas concejiles de iniciar reformas en el Consejo y la Chancillería y así figuraban en la memoria presentada por los procuradores de Cortes en 1480:

..Item V.M. debe reformar mucho vuestro alto consejo e chancillería de perlados e cavalleros e letrados de autoridad e de conciencia e de ciencia que esten estantes sin tener otras ocupaciones. E para esto se debe de entender que estos sean bien pagados e sostenidos, pues en ellos va la mayor partee de la gobernación de los reinos e descargo de vuestras conciencias e famas ${ }^{35}$.

En este sentido, proponían que el rey participase en el mismo un día a la semana y que ese día se viesen todas las cuestiones relativas a violencia para poderlas remediar antes y con mayor efectividad. También se pedía remedio para la justicia de la Corte para que los oficiales diesen ejemplo a todos los del reino, posiblemente, haciendo alusión a la profesionalidad requerida. La creciente presencia de oficiales de la justicia conocedores del derecho prueba una tendencia de mayor certeza en el planteamiento de los asuntos jurídicos y de gobierno. No olvidemos que originariamente los ámbitos de capacidad normativa de las ciudades eran de derecho privado, derecho penal, defensa y fiscalidad y que paulatinamente la reacción regia buscaba engullir la normativa local en la pesada máquina de su legislación. Pero las ciudades habían reaccionado en defensa de su capacidad normativa durante el período trastámara, al tiempo que se habían mostrado colaboradoras en la difusión de las leyes regias aprobadas en Cortes. Lo cual, también prueba el papel de apoyo de las ciudades a la monarquía y su contribución a la formación de un solo cuerpo legislativo. Por otra parte, a medida que la vida administrativa se hacía más compleja se imponían los juristas, notarios y oficiales, en tanto que profesionales universitarios conocedores del derecho. Lo prueba el reclutamiento de letrados y escribanos para la gestión y organización se los asuntos de Cortes, entre los que participaron relevantes juristas que también eran miembros del Consejo Real ${ }^{36}$.

Junto a estos importantes oficiales se encontraba el conjunto de los modestos oficiales, servidores necesarios para el funcionamiento del aparato administrativo: escribanos, porteros, alguaciles, aposentadores. Hombres de extracción social más modesta que realizaban tareas diversas y que generalmente eran reclutados en el seno de los grupos oligárquicos. Por lo general,

\footnotetext{
${ }^{34}$ Sobre la función del Consejo Real: S. DE DIOS, El Consejo Real de Castilla (1385-1522), Madrid, Centro de estudios constitucionales, 1982 e Instituciones centrales, op. cit. p. 253. La participación de los representantes de las ciudades en el Consejo real en: M. ASENJO GONZÁLEZ, El poder regio y las ciudades castellanas, op. cit., pp. 947-955.

${ }^{35} \mathrm{D}$. CLEMENCIN, Elogio de la Reina Católica, op. cit; Memoria que dieron los procuradores de Castilla a los Reyes en Toledo año de 1480, domingo seis de febrero. Al principio de su reinado, p. 596.

${ }^{36}$ Es el caso del doctor Alcocer y los licenciados Zapata y Tello: S. DE DIOS, Instituciones centrales, op. cit., p. 282 y nota 45.
} 
estos colaboradores en la gestión y administración del reino actuaban en villas y ciudades, arraigaban en ellas y lograban construir patrimonios familiares y fortunas que en algunas ocasiones les permitían formar mayorazgo a favor de sus descendientes. En general, formaban el sustrato social del que emergerá la llamada "nobleza de toga" ${ }^{37}$. Un grupo todavía poco conocido en su comportamiento social de afinidades políticas singulares y conocedores de las posibilidades de maniobra en el marco de las ciudades y su territorio, y cuya percepción política resulta interesante, al localizarse entre ellos las opiniones que muestran un mejor conocimiento de los problemas políticos del reino y de las posibilidades de éxito de los tratados y acuerdos, mostrandose, en algunos casos, más reivindicativos e innovadores en sus planteamientos. ${ }^{38}$ Ese mismo compromiso lo observamos en algunas de las primeras misivas que se le envíaron al joven rey Carlos para informarles de los asuntos del reino ${ }^{39}$. Sin olvidar que los notarios también resultaron ser hombres clave en la vida pública ya que conocían los detalles del gobierno de los asuntos cotidianos, tanto los inmediatos como los que pudieran venir ${ }^{40}$.

También el control y la defensa del territorio eran asuntos primordiales para los concejos de realengo, que se habían forjado en esos propósitos casi desde sus orígenes, si bien, en el período bajomedieval, se habían ampliado y perfeccionado sus atribuciones ${ }^{41}$. En Castilla, casi la mitad de los territorios y al menos la tercera parte de la población vivía en señoríos, pero las grandes villas y ciudades no fueron señorializadas y, aunque la jurisdicción señorial ocupaba la mayor extensión geográfico-espacial no tenía los mayores efectivos poblacionales. Estos se encontraban en el territorio de realengo, en el conjunto de los concejos y ciudades del reino. Desde mediados del siglo

${ }^{37}$ M. ASEnJo GonZÁlez, Segovia. La ciudad y su tierra a fines del Medievo. Segovia, Exma. Dip. Prov. Segovia y otros, 1986. En este trabajo tuvimos oportunidad de reconocer la fortuna de uno de los secretarios del concejo de Segovia que entre 1424 y 1514 adquirió un importante patrimonio en tierras en la localidad Segoviana de Tavanera la Luenga, pp. 406-407.

${ }^{38} \mathrm{Al}$ grupo de los juristas universitarios más destacados del reino pertenece la figura de Fernando de Roa uno de los ideólogos de las reivindicaciones comuneras, que defendía con argumentos que la monarquía debía de ser electiva y que los medianos debían de hacer valer su posición y voz política en los asuntos del gobierno del reino. Ver la obra de J.L. CASTILLO VEGAS, Política y clases medias: El siglo XV y el maestro salmantino Fernando de Roa. Valladolid, Universidad de Valladolid, 1987.

${ }^{39} \mathrm{M}$. ASENJO GONZÁLEZ, Las ciudades castellanas al inicio del reinado de Carlos V, "Studia Historica. Historia Moderna”, 21 (1999), pp. 49-115, pp. 74-75.

${ }^{40} \mathrm{~A}$. RIGAUdière, Gouverner la ville au Moyen Age. París, 1993, p. 151. Sobre notarios castellanos ver el reciente trabajo de D. IGUAL LUIS, Las perspectivas de investigación sobre fondos notariales en Castilla, en Perspectivas actuales sobre las fuentes notariales de la Edad Media. Aragón en la Edad Media, Zaragoza, Univ. de Zaragoza, 2004., pp. 127-152.

${ }^{41}$ La compenetración de elementos feudoseñoriales, urbanos y estatales de la construcción de la sociedad política, haciendo crítica al hecho de que se ha ido demasiado lejos en aceptar la permanencia y continuidad de los elementos señoriales y feudales, y en la senorialización del conjunto de la sociedad como paradigma explicativo de la historia peninsular. Así lo destaca P. IRADIEL, Señoríos jurisdiccionales y poderes públicos, op . cit., p. 72 . Sobre ciudad y territorio ver nuestro trabajo: Ciudad y territorio en la Castilla bajomedieval. Dinámica socioeconómica, en El poder a l'Edat Mitjana. VIII Curs d'Estiu Comtat d'Urgell (Balaguer 9-10 $i$ 11 de juliol), ed. F. SABATÉ, Lleida, Univ. de Lleida y otros, 2004, pp. 141-176 y J.A. SOLORZANO TELECHEA; B.E. ARIZAGA BOLUMBURU, (eds), El fenómeno urbano entre el Cantábrico y el Duero. Revisión historiográfica y propuestas de estudio, Santander, Asociación de jóvenes historiadores de Cantabria, 2002. 
$\mathrm{XV}$, se observan los efectos de la señorialización creciente sobre el conjunto de las ciudades y villas del que se habían salvado las más fuertes, mientras las más modestas habían caído en dependencia señorial ${ }^{42}$. No obstante la presión de la nobleza sobre las ciudades de realengo no se detuvo sino que incluso se acrecentó en la segunda mitad de la centuria ${ }^{43}$.

En la convivencia con otras jurisdicciones, como la señorial o la eclesiástica, se observa, a través los conflictos y las reclamaciones de vecinos y concejos, que solicitaban la intervención regia para solucionar diferencias. En ese sentido, se expresaban cuando protestaban por los irregulares criterios de aplicación de las normas del derecho eclesiástico, que consideraban suponía un freno para los derechos de los laicos, y por las consecuencias de la aplicación de un derecho gravoso en algunos aspectos.

Por su parte, las ciudades y villas de realengo procedieron a un despliegue de las competencias asociadas al señorío colectivo, como legislativas, fiscales y militares. Así, cabe destacar la mencionada colaboración y la actitud favorable de los concejos a algunos cambios introducidos a lo largo de todo el reinado. No sólo en la aplicación de las disposiciones regias sino en la regulación de cuestiones de interés general que correspondían a su regalía, como los criterios acerca del valor de las monedas, la elección de oficiales de justicia y gobierno locales: alcaldes, merinos y adelantados, la liberación de trabas al paso de los ganados y de las mercancías, con el consiguiente levantamiento de montazgos y pontazgos. Asuntos asociados a la autoridad del poder regio pero que requerían también el apoyo concejil en algunos aspectos. Pero esa solicitud de colaboración en dichas competencias no restaba fuerza al ejercicio de las atribuciones que seguían siendo competencia del señorío colectivo que mantenían ciudades y villas de realengo. Así, no dudaban en pedir que les fuera restituido el control sobre las fortalezas, que en algunas ciudades se encontraban ocupadas, con el propósito de podérselas entregar a los naturales. Al parecer, las primeras intervenciones que los reyes Católicos realizaron fueron consecuencia de la política de pacificación de bandos nobiliarios que siguió a los acontecimientos de la guerra civil (1476$1479)^{44}$. En el caso de las ciudades que tenían conflictos y enfrentamientos, la mediación regia se consideró necesaria aunque excepcional, pero lo cierto es que los reyes supieron sacar provecho de esas situaciones para acabar cercenando y reduciendo los privilegios que las ciudades habían mantenido en

\footnotetext{
${ }^{42}$ J.M. MONSALVO ANTON, Centralización monárquica castellana y territorios concejiles (Algunas hipótesis a partir de las ciudades medievales de la región castellano-leonesa, "Anales de la Universidad de Alicante. Historia Medieval", 13 (2000-2002), pp. 157-202.

${ }^{43}$ M.C. QUINTANILLA RASO, Estructuras sociales y familiares y papel político de la nobleza cordobesa (siglos XIV y XV), "En la España Medieval", III/2 (1982), pp. 331-352.

${ }^{44}$ En el reino de Sevilla, particular desde 1477, asegura F. GARCIA FITZ; M. ROJAS GABRIEL, Las tenencias de las fortalezas del concejo sevillano en época de los Reyes Católicos: un aspecto del fortalecimiento del poder real, en La Península Ibérica en la era, op. cit., pp. 737-766, p.
743 .
} 
cuanto a los nombramientos de tenentes y alcaides de las fortalezas de su término, en un lento proceso que duraría veinte años más ${ }^{45}$.

El mantenimiento de usos y costumbres, junto con la preservación de los privilegios otorgados a los lugares del reino, era algo aceptado por los reyes, si bien había entrado en contradicción con las capacidades reconocidas en el Ordenamiento de Alcalá que se resolvía con la prelación legislativa. No obstante, esas mismas pautas liberaban altas competencias normativas en el marco local para los concejos de realengo, que por medio de ordenanzas y disposiciones regulaban muchos asuntos de su interés. Los Reyes Católicos mantuvieron esa misma práctica y favorecieron su capacidad legislativa que posteriormente ratificarían con el reconocimiento y promulgación de las leyes y ordenanzas locales ${ }^{46}$.

En cuanto a las atribuciones fiscales, se trataba de competencias fuertemente arraigadas en los concejos castellanos que se potenciarían enormemente en este reinado, siguiendo una pauta ya iniciada en los reinados de Juan ii y Enrique iv ${ }^{47}$. En especial, se fueron incrementando a medida que las ciudades asumían más competencias asociadas al ejercicio del señorío colectivo que gobernaban ${ }^{48}$. La mecánica de recaudación de algunos impuestos reales implicaba a las ciudades y villas en la percepción y muy especialmente el de la alcabala, al concederles a los concejos el encabezamiento de esta renta, tal y como se hiciera con antelación a favor de los señoríos jurisdiccionales laicos y eclesiásticos ${ }^{49}$. Ello favorecía a las ciudades, en tanto que reducía el monto de la renta, al fijarla en una cantidad apreciada sobre años anteriores, y también acababa con la intermediación de los desacreditados recaudadores, que suponían un lastre para la administración y concitaban el odio de los vecinos contribuyentes. Así, se generalizaron las innovaciones que se habían iniciado en el reinado de Enrique iv para recaudar la renta real de la alcabala. Pero esa renta, a fines del siglo XV, se quedaba repartida en casi su totalidad en las ciudades y su territorio próximo, al ser percibida por los miembros de las oligarquías locales y otros perceptores, que poseían los "juros" establecidos en ella; ya los hubieran obtenido por concesión regia en

\footnotetext{
${ }^{45}$ Así se ha comprobado para el caso de Sevilla: Ibídem, p. 745.

${ }^{46}$ J.A. BONACHIA HERNANDO, El concejo como señorio (Castilla, siglos XIII-XV), en Concejos y ciudades en la Edad Media hispánica. II Congreso de Estudios Medievales, León, Fund. Sánchez Albornoz, 1990. pp. 431-463.

${ }^{47} \mathrm{~F}$.J. ROMERO ROMERO, El Concejo como instrumento de la fiscalidad regia en la Castilla del siglo XV. Sevilla y los pedidos de cortes: 1406-1474, en Actas del VI coloquio internacional de historia medieval de Andalucía: las ciudades andaluzas, siglos XIII-XVI (Estepona, 1990), eds. J.E. LOPEZ DE COCA; A. GALÁN SÁNCHEZ, Málaga, Univ. de Málaga, 1991.pp. 161-166 y Y. GUERRERO NAVARRETE, Fiscalidad regia y poder municipal en Burgos (1453-1476), "En la España Medieval”, 8 (1986), pp. 481-499.

${ }^{48}$ A. COLLANTES DE TERÁN, Los estudios sobre las haciendas concejiles españolas en la Edad Media "Anuario de Estudios Medievales", 22 (1992), pp. 323-340 y Y. GUERRERO NAVARRETE, Fiscalidad de ámbito municipal en las dos Castillas (siglo xiv y xv): estado de la cuestión, "Medievalismo", 11 (2001), pp. 225-278.

${ }^{49}$ M. ASENJO GONZÁLEZ, Los encabezamientos de alcabalas en la Castilla bajomedieval. Fuentes de renta y política fiscal en Fiscalidad de Estado y fiscalidad municipal en los reinos hispánicos medievales, Eds. D. MENJOt y M. SÁnCHEZ, Madrid, Casa de Velázquez, 2006, pp. 135-170.
} 
privilegio o por compra, siguiendo una modalidad de inversión similar a los censales de Cataluña ${ }^{50}$.

La estructura de las provincias fiscales, en tanto que demarcaciones, con una ciudad de realengo al frente, se convertiría en el mosaico organizativo de utilidad recaudatoria y fiscal,que se pensaba debía dar paso a la construcción de un ejército real estable de infantería armado con espingardas (armas de fuego), llamado a tener un papel definitivo en la guerra moderna ${ }^{51}$. Pero aquello fue el inicio de un proyecto frustrado que se retomaría en tiempos de la regencia de Cisneros y que provocaría revueltas y tensiones en algunas ciudades del reino, como ocurrió en Valladolid en $1516^{52}$.

Tal y como se ha apuntado anteriormente, los concejos se convertirían en el referente para la organización del ejército permanente que ambicionaba cualquier monarca de la época y que se empezaba a poner en marchar con cierta premura. Fue justamente al finalizar la guerra de Granada cuando se tomaron las primeras medidas, anunciando las campañas europeas de los próximos decenios ${ }^{53}$. Es cierto que los concejos ya se habían volcado en la colaboración para la conquista de Granada ${ }^{54}$. A esto se añadiría la fuerza de la Hermandad, de organización concejil en la construcción militar del reino y su papel en los primeros pasos hacia la formación de un ejército permanente. Ya en 1480 los procuradores de los concejos con presencia en Cortes estaban convencidos de la necesidad de contar con un ejército eficaz capaz de remediar los asuntos de la guerra con la profesionalidad de hombres diestros y formados ${ }^{55}$. Es cierto que su propuesta coincidía con la ambición monárquica, pero también es muy probable que les animara la intención de resolver de una manera estable los inconvenientes de los alardes y levas, y también del alto coste de las operaciones militares sufragadas por medio de los servicios de Cortes. A medio plazo esta reforma minaba seriamente las bases de referencia del poder oligárquico de los caballeros villanos, en tanto que practicaban un oficio de armas a caballo, asociado a la exención y al privilegio, y que había sido una las bazas fundamentales en la promoción social urbana y de diferenciación, en el seno de la propia sociedad oligárquica.

\footnotetext{
${ }^{50}$ J. AguAdo DE los ReYes, Los capitales sevillanos, op. cit., p. 490 y ss.. 1975 .

${ }^{51} \mathrm{R}$. PUDDU, Eserciti e monarchie nazionali nei secoli $X V-X V I$, Firenze, La Nouva Italia,

${ }^{52}$ M. ASENJo GONZÁLEZ, Las ciudades castellanas al inicio, op. cit., pp. 106-110.

${ }^{53} \mathrm{R}$. QUATREFAGES, A la naissancede l'armée moderne, "Melanges de Casa de Velázquez", 13 (1977), pp. 119-159.

${ }^{54}$ M.A. LADERO QUESADA, Milicia y economía en la guerra de Granada op. cit. y Castilla y la conquista del reino de Granada. Granada, Dip. Prov. de Granąa, 1988; E. BENITO RUANO, Aportaciones de Toledo a la guerra de Granada. "Al-Andalus", 25 (1960), pp. 41-70; M. GONZÁLEZ JIMENEZ, La guerra en su vertiente andaluza: participación de las ciudades, villas y señoríos andaluces, en La Incorporación de Granada a la Corona de Castilla: Actas dél Symposium conmemorativo del Quinto Centenario (Granada, 2 al 5 de Diciembre de 1991), ed. M.A. LADERO QUESADA, Granada, Diputación Provincial, 1993, pp. 651-674.

${ }^{55}$ D. ClemenCín, Elogio de la Reina Católica, op. cit., Memoria de los procuradores de las Cortes de Toledo, 1480, p. 597: "Item deben facer hombres de armas porque en la paz deben remediar las cosas para la guerra necesarias, y que estén diestros y ejercitados en las armas, y que esto se hiciese continuamente é non usasen oro ni seda para vestir, sino paños comunes e las armas".
} 
El nuevo ejército vaciaba de contenido sus preeminencias y exenciones y, lo que parece más importante, frenaría los efectos de promoción social más eficientes de la historia medieval de Castilla.

Vemos que todas las opciones de colaboración en la gobernabilidad del reino potenciaban nuevas competencias y responsabilidades de las ciudades en relación, no sólo con la demarcación de su territorio y jurisdicción, sino en el marco más amplio de la provincia o de las tierras señoriales sujetas a la obligación contributiva o militar con la monarquía.

Desde una perspectiva social, se observa el predominio de una oligarquía inquieta que percibe con temor la promoción social creciente y el encumbramiento de algunos de sus miembros como consecuencia del enriquecimiento y de la protección otorgada por alguno de los grandes o del monarca ${ }^{56}$. Pero incluso, dentro de la propia sociedad oligárquica, actuó como elemento de despegue y promoción social la fuerte aristocratización que la monarquía había potenciado, en particular desde 1419. A fines del siglo XV, las tensiones internas se explican por el posicionamiento de algunos de los sectores de la oligarquía local más beligerantes en contra del despegue protagonizado por los elegidos como miembros del Consejo Real. Órgano que desde 1419 actuaba como órgano de representación estamental, que vaciaba de contenido a las propias Cortes del reino ${ }^{57}$. De hecho, ese malestar generado se percibe claramente en el tono de las intervenciones de los procuradores urbanos que acuden a las restauradas Cortes de en Córdoba (1455) y Toledo (1462), en el reinado de Enrique iv y muy particularmente en las de Ocaña de 1469. La voluntad de restablecer la función de las Cortes como puente de diálogo entre rey y reino se recupera en ese reinado, una vez que se habían hecho los necesarios reajustes internos en las propias ciudades y en el seno sus oligarquías dominantes $^{58}$. En esas circunstancias, se comprende, que las 17 ciudades de realengo que habían estado en el primer plano de las decisiones políticas del reino, participasen con entusiasmo en desarrollar un modelo político de gobierno de marcado carácter aristocrático instaurado por los Trastámaras desde Enrique iii y se puso a punto bajo Juan ii (1406-1554). Tras el paréntesis del confuso reinado de Enrique iv, los Reyes Católicos pretendían conservar y potenciar esas opciones políticas de creciente

\footnotetext{
${ }^{56}$ ÍDEM Oligarquías urbanas en Castilla en la segunda mitad del siglo XV, en Actas del Congresso Internacional "Bartolomeu Dias e a sua época, IV, 1989, pp. 413-436; J.C. MARTín CEA; J.A. BONACHÍA HERNANDO, Oligarquías y poderes concejiles en las en la Castilla bajomedieval: balance y perspectivas, "Revista d'Historia Medieval", 9 (1998), pp. 17-40; J. VALDEON BARUQUE, Las oligarquías urbanas, en Concejos y ciudades..., op. cit., pp. 509-521.

${ }^{57} \mathrm{M}$. ASENJO GONZÁLEZ, El poder regio y las ciudades castellanas, op. cit. 953-955 y La aristocratización política en Castilla y el proceso de participación urbana (1252-1520), en La monarquía como conflicto en Castilla (1250-1450), ed. J.M. NIETO SORIA, Madrid, Silex 2006, pp. 133-196. Una relación equivalente de comunicación institucional entre Consejo y Cortes encuentra J. CARRETERO ZAMORA, Cortes, monarquía, ciudades, op. cit. p.165.

${ }^{58}$ Entre 1464-1466 Burgos se dio un nuevo marco institucional: J. PARDOS MARTínEZ, Constitución politica y Comunidad en Burgos a finales del siglo XV (Reflexiones en torno a un documento de 1475), en La ciudad hispánica durante los siglos XIII al XVI, I (1985), pp. 545580 .
} 
aristocratización con el ambicioso objetivo de atraer voluntades a su causa y en la medida en que las nuevas circunstancias lo hacían necesario.

\section{LAS OCASIONES DE PLASMACIÓN DE LA COLABORACIÓN: RELACIONES DE PACTO O SERVICIO}

El interés de las partes en coincidir en el desarrollo de la política del reino parece evidente desde 1480, cuando en las Cortes de Toledo se busca un marco de colaboración que permita desplegar las potencialidades de ambos poderes, que lejos de ser concurrentes parecían llamados al entendimiento y que en algunos asuntos se comprobó que se potenciaban y complementaban sin grandes dificultades. Las ocasiones de plasmación de ese buen entendimiento aparecieron en el panorama político del reino justamente al acabar la guerra civil de 1476-1479 y poder disponer las nuevas bases para esa gobernabilidad. Aquí es donde se justifica la colaboración que las ciudades ofrecen a la monarquía, no sin antes exigirles ciertos compromisos de gobierno que se expresaban de un modo genérico sobre argumentos que aconsejaban que el comienzo del orden social debía empezar por las propias personas regias para repartir el tiempo en tres partes: para lo divino, para oír y despachar con vuestros súbditos, asignándoles otras personas para negociar a fin de evitar su enojo y finalmente para la propia recreación regia, con el argumento de:

pues sois reyes no aveis siempre de holgar, e pues sois humanos no aveis siempre de trabajar ${ }^{59}$.

Una reflexión acorde con el esquema del cuerpo humano, que para reflejar las diferentes partes del organismo político y que sitúa a los súbditos del rey en el primer plano de su interés desplazando a los miembros de los otros estamentos sociales que conformaban el orden del antiguo régimen. Pero a esa conclusión se llega tanto desde la vía del servicio debido, en tanto que obligación feudovasallática, o bien como pacto y acuerdo que subyace en el trasfondo de la imagen política de la sociedad estamental ${ }^{60}$. Si bien es cierto que ambas pudieron contribuir a perfilar los comportamientos políticos de las ciudades respecto al poder regio.

De ese modo, cabe considerar a las Cortes de Toledo de 1480 como el gran programa político que los reyes incorporaron a la gobernación del reino tras el final de la guerra civil ${ }^{6}$. Para entonces, las dificultades para

${ }^{59} \mathrm{D}$. CLEMEnCín, Elogio de la Reina Católica, Doc. 8: Memoria que dieron los procuradores de Castilla a los reyes en Toledo, 3 febrero 1480. p. 595.

${ }^{60} \mathrm{~J}$.M. MONSALVO ANTÓN, La baja Edad Media en los siglos XIV y XV: Política y cultura, Madrid, Síntesis, 2000; M. AŚENJO GONZÁLEZ, El Estado y la distribución del poder, op. cit.,

${ }^{61}$ Desde esta perspectiva han sido estudiadas por J. CARRETERO ZAMORA, Cortes, monarquía, ciudades, op. cit., p. 150. 
reconstruir las negociaciones a gran escala recayeron en los miembros del Consejo de Castilla, presidido por Pedro González de Mendoza, y al parecer las aspiraciones de las ciudades apenas dieron problemas, si bien entrarían en conflicto con la Corona por tres razones: la figura del corregidor, la delimitación de términos y el alcance de la política reductora de mercedes, que posiblemente afectaba a los propios. También hubo tensiones en el acuerdo con los estamentos privilegiados, ya que la nobleza y el clero no cortesano tenían motivos para recelar de la reducción de los juros y mercedes emprendida a petición de los procuradores urbanos. Finalmente, los procuradores de las ciudades se resignaron para evitar males mayores, al comprender las necesidades de la hacienda real y también por la tibieza de la medida.

En 1480, la aprobación de los capítulos de Cortes contribuyó a crear conciencia de que la nueva monarquía tenía un programa de gobierno y había logrado por su voluntad romper una actuación política anterior presidida por él desorden, la inseguridad y la injusticia. En este sentido, cabe recordar que se utiliza el término "bien común" para aludir a la actitud de los procuradores y justificar así su posición política ${ }^{62}$.

Pocas convocatorias del Cortes del reinado tuvieron lugar entre 14981506, período en el que esa escasa actividad coincide con la decadencia del Consejo que se sustituye por los secretarios reales y contadores mayores y embajadores, etc.. Se volvieron a reunir cortes en Toledo en 1502 para jurar a la princesa doña Juana, aunque ya se sabía de su incapacidad. En cuanto a las Cortes de Madrid de 1503 fueron la continuación de las de 1502, ya que asistieron los mismos procuradores y no se hizo para ellos una convocatoria expresa $^{63}$. Por otro lado, el testamento de la reina ya dejaba traslucir la cuestión de la incapacidad de Juana, al otorgar al rey el reconocimiento de gobernador y por las obligaciones que se le exigían, al equipararle a los monarcas y quedar obligado a no enajenar el patrimonio real, guardando los privilegios, usos y costumbres de las ciudades y villas ${ }^{64}$. Finalmente, a la muerte de Isabel en 1504, las Cortes de Toro de 1505 fueron importantes en el desarrollo normativo de Castilla por establecer la instauración del mayorazo y fijar con precisión la prelación de fuentes a utilizar en la aplicación del derecho, entre otros asuntos.

${ }^{62}$ obre el concepto de "bien común": P. BLICKLE, El pricipio del "bien común"como norma para la actividad política. (La aportación de campesinos y burgueses al desarrollo del Estado Moderno temprano en Europa Central), "Edad Media. Revista de Historia”, 1 (1998), pp. 29-46. J.A. BONACHIA HERNANDO, La justicia en los municipios castellanos medievales, "Edad Media. Revista de Historia Medieval", 1 (1998), pp. 145-182. Opina que un buen gobierno es un gobierno justo, unido al bien común.

${ }^{63}$ J. CARRETERO ZAMORA, Cortes, monarquía, p. 504 y ss.

${ }^{64} \mathrm{M}$. ASENJO GONZÁLEZ, Ciudades y oligarquía urbana en Castilla en los años de la "Gobernación” de Fernando el Católico (1506-1516), en Sardegna, Spagna e Mediterra eo Da Rei Catt 142 . 


\section{CONFLiCTOS Y DESENCUENTROS}

Desde 1480 se habían puesto las bases de una colaboración política e institucional entre monarquía y ciudades que se ampliaría en el futuro, a medida que la monarquía recababa por medio de disposiciones y ejecutorias las responsabilidades urbanas en un amplio abanico de competencias, que se fueron incrementando en el curso de los años venideros. Esa realidad se comprueba a lo largo de todo el reinado, el hecho de que las ciudades y villas de realengo fueron fundamentales para la afirmación del poder regio y lo seguirían siendo en el futuro. Tampoco había dudas en cuanto a la potencialidad urbana y a la necesidad que la nueva monarquía tenía de su útil colaboración. Ahora bien, si al inicio del reinado la aportación urbana se hacía en clave de colaboración deducida de la ambición individual de privanza, privilegios y fortuna, eso mismo generaba una expectativa en los grupos dominantes y en particular en la oligarquía urbana, que se sentía enormemente atraída por las posibilidades que el nuevo reinado ofrecía para volcarse en el servicio y alcanzar la privanza regía ${ }^{65}$. Pero no olvidemos que esas expectativas creadas buscaban apoyos sustanciales de unos monarcas que se encontraban faltos de legitimidad política ${ }^{66}$.

Lo cierto es que esa convincente expectativa chocó frontalmente con los modos y maneras en que la monarquía de los reyes Católicos planteaban las relaciones de colaboración en las tareas de gobierno del reino. Unas maneras que se atenían a criterios de mayor participación urbana, al asumir cada vez más competencias, y en los que introdujeron criterios de eficacia, en una tendencia social igualadora que cuestionaba el diferenciado carácter de las relaciones de colaboración y servicio de otros reinados. Con esas posibilidades, es cierto que numerosos miembros de la oligarquía urbana lograrían cargos complementarios en su trayectoria política, asociados al gobierno y la gestión, como corregimientos, alcaldías, secretariados, tenencias de fortalezas, etc. Siempre en función de su preparación y competencias. Pero estos cargos eran entregados individualmente y para un tiempo y unos cometidos concretos. De ellos se beneficiaban regidores urbanos y miembros de la aristocracia, hidalgos y caballeros, pero los reyes combinaban esa actitud con medidas que recababan competencias colectivas de designación de cargos,

\footnotetext{
${ }^{65}$ Resulta bien conocido el "servicio" que jugó una función clave en la articulación social de la aristocracia inglesa: J.M.W. BEAN, From Lord to Patron. Lordship in Late Medieval England. Manchester, Manchester Univ. Press, 1989; R. HORROX, Service, en Fifteenth-century attitudes. Perceptions in Late Medieval England, ed. R. HORROX, Cambridge, Cambridge Univ. Press, 1994, pp. 61-78.; C. JULAR PÉREZ-ALFARO, La participación de un noble en el poder local a través de su clientela. Un ejemplo concreto a fines del siglo XIV, "Hispania", 53/185 (1993), pp. 861-884. En cuanto a la privanza regia y sus posibilidades para los grupos dominantes urbanos ver: S. DE MOXO Y ORTIZ DE VILLAJOS, El auge de la nobleza urbana de Castilla y su proyección en el ámbito administrativo y rural a comienzos de la baja Edad Media, "Boletin de la Real Academia de la Historia", CLXXVIII/III (1981), pp. 407-518.

${ }^{66}$ Recordemos que durante la instauración trastámara se había producido el mayor auge de la nobleza en Castilla. Una reciente revisión en: J. VALDEÓN BARUQUE, Los Trastámaras. El triunfo de una dinastía bastarda, Madrid, Temas de Hoy, 2001; A.I. CARRASCO MANCHADO, Isabel.I de Castilla y la sombra de la ilegitimidad. Propaganda y legitimación en el conflicto sucesorio (1474-1482), Madrid, Silex, 2006.
} 
que antes recaían en los concejos y ciudades del reino ${ }^{67}$. Por lo tanto, la expectativa de promoción, siempre necesaria en la colaboración clientelar, siguió funcionando entre sus miembros, lo que les permitía mejorar las opciones de acceso a cargos menores que retroalimentaban a los miembros de sus respectivos grupos de clientela. Pero también es preciso reconocer que los reyes aplicaban a muchas de sus medidas criterios de igualitarismo selectivo, que rompían con las ocasiones de promoción o enriquecimiento diferenciado que resultaron ser un punto fundamental en la tradicional colaboración de servicio al monarca.

La demanda de colaboración de la monarquía se atendría así a nuevos criterios de rectitud. Recordemos que los Reyes Católicos adquieren legitimidad política a partir de su victoria en la guerra civil y del restablecimiento de la paz y la justicia en el reino, realidades que serían reconocidas en 1480. Pero, a partir de entonces, los reyes pasarían a reinar por derecho divino, posición que también se lograba porque sus súbditos los confirmaron como beneficiarios. Las Cortes de 1480 fueron, por tanto, el marco de la génesis de una monarquía moderna en Castilla, evidenciada en tres rasgos: la sacralización del poder, el reconocimiento de ese poder por la comunidad, materializado por las élites y la conexión de los propósitos monárquicos con los sentimientos profundos de esa comunidad: conquista de Granada, lucha contra el turco, etc ${ }^{68}$.

En cuanto a los modelos equitativos utilizados en la sociedad del privilegio y a la aplicación de la justicia, se convertirían en asuntos fundamentales y objetivo de observación política de primer orden, ya que de ellos dependían la pacificación civil y ayudarían en mucho a la consolidación de un poder regio de nuevo cuño ${ }^{69}$. Por ello se explica que los Reyes Católicos dieran tanta importancia a la reforma de las instituciones del Consejo y la Chancillería. Seguida de una organización de la política administrativa que ha sido calificada como situada entre la tradición y la modernidad ${ }^{70}$.

La ampliación de la base social de los posibles colaboradores regios actuaría como soporte político del reinado, al tiempo que el beneficio de los juros, que podían ser comprados o adquiridos, sobre rentas reales, proporcionó un sólido colchón de estabilidad social y se convertiría en otro de los pilares fundamentales de la gobernabilidad del reino. Este aspecto, que se

\footnotetext{
${ }^{67}$ F. GARCIA FITZ; M. ROJAS GABRIEL, Las tenencias de las fortalezas proporcionan el ejemplo de su interés por designar alcaldes y tenentes de las fortalezas asumiendo competencias que habian correspondido al concejo de Sevilla desde el siglo XIII, pp. 758-766.

${ }^{68}$ J. CARretero ZAMORA, Cortes, monarquía, p. 158.

${ }^{69} \mathrm{La}$ aplicación de la gracia regia como excepcionalidad del procedimiento reforzaba su autoridad: S. DE DIOS, El ejercicio de la gracia regia en Castilla entre 1250 y 1530 : los inicios del Consejo de la Cámara, "Anuario de Historia del Derecho Español", 60 (1990), pp. 323-351.

${ }^{70}$ Los cometidos de gracia y merced regia se presentan con amplísimas posibilidades en su reinado ya que abarcaba: concesiones de nobleza, provisiones de oficios públicos, çartas de naturaleza, perdones, legitimaciones, mayorazgos, licencias, habilitaciones, dịspensas, intervenciónes en la administración de justicia que podía llegar hasta la avocación o el sobreseimiento de pleitọs, las mercedes en oficios dineros o jurisdicciones, o las confirmaciones regias de actos o negocios jurídicos defectuosos. IDEM, Instituciones centrales de gobierno, op. cit., p. 255.
} 
justifica socialmente por las buenas condiciones económicas del período y la escasez de trabas sociales para la promoción social, al inicio del reinado, resulta más difícil de seguir en el marco de la política regia debido a la importancia que alcanzaron algunas medidas de promoción aristocrática. Pero, sin duda, en ellas los reyes Católicos buscaron más favorecer a personajes de su entorno o comprometidos con la causa monárquica dentro del marco local, que a los miembros de la propia oligarquía urbana en el poder. Su política no fue siempre favorable a esas añejas redes de poder, que en el marco de la ciudad y de su tierra jugaban un papel articulador, y se consideraban representantes del los valores urbanos. En muchas ocasiones generó en ellas descontento algunas disposiciones como la ampliación por concesión regia del número de regimientos otorgados a sus fieles vasallos.

Los reyes también facilitaron la patrimonialización de los cargos de regidores y su venta ${ }^{71}$. Pero, en cierto sentido, la nueva política contribuyo a desarticular algunos de los modelos tradicionales de convivencia, al tiempo que vaciaba de contenido una de las prebendas más necesarias del poder oligárquico como el control de las rentas y cargos del concejo, sobre cuyo beneficio o expectativa se construía en clave de integración la misma red de clientela local $^{72}$.

En esas nuevas circunstancias se hacía necesario el "bálsamo" de la propaganda política ${ }^{73}$. Asunto al que los reyes dedicaron gran atención hasta el final del reinado, volcados tanto en asegurar la legitimidad dinástica como en potenciar la figura regia y algunas de sus medidas más polémicas. No obstante en el recuerdo de los teóricos políticos urbanos permanecieron dos referentes fundamentales de compromiso político: el testamento de Isabel la Católica, por una parte, junto a las Cortes de 1480, por otra. Ambos se tenían como bases de los acuerdos pactados entre monarquía y ciudades y así lo expresaban los comuneros en la Junta de Burgos de $1520^{74}$.

\section{CONCLUSIÓN}

La participación de las ciudades en la gobernabilidad del reino no se conseguiría como reacción inmediata de sometimiento al poder autoritario de

\footnotetext{
${ }^{71} \mathrm{~F}$. TOMÁS Y VALIENTE, Origen bajomedieval de la patrimonialización y la enajenación de oficios públiços en Castilla. en Actas del I Symposium de Historiade la Administración (Madrid 1970), Madrid, 1970, pp. 141-2; B. GONZÁLEZ ALONSO, La reforma del gobierno de los concejos en el reinado de Isabel, en Isabel la Católica, op. cit., pp. 293-312.

${ }^{72}$ J.M. MONSAlvo ANTÓN, La sociedad política en las concejos castellanos de la Meseta durante la época del régimiento medieval. La distribución social del poder, en Concejos y ciudades en la Edad Media hispánica. II Congreso de Estudios Medievales, León, Fund. SánchezAlbornoz, 1990, pp. 358-413.

${ }^{73}$ J.M. NIETO SORIA, Propaganda política y poder real en la Castilla Trastámara: una perspectiva de análisis, "Anuario de Estudios Medievales", 25/2 (1995), pp. 489-516; IDEM y A.I. CARRASCO MANCHADO, Bibliografía [Orígenes de la monarquía hispanica: propaganda y legitimación], en Orígenes de la monarquía hispánica, op. cit., pp. 535-589.

${ }^{74} \mathrm{M}$. ASENJO GONZÁLEZ, Las ciudades, en Orígenes de la Monarquía hispánica, op. cit., pp. 105-141. y La aristocratización política en Castitla, op. cit., pp. 188-193.
} 
los Reyes Católicos sino que se atuvo a unas pautas de acuerdo y colaboración necesaria para las partes e interesante para cada una de ellas. Ciertamente, las buenas expectativas que ofrecía a los poderes urbanos esa implicación en los asuntos de gobierno se unieron a una buena situación económica, que facilitaba el cambio y la promoción social en todos los grupos, al tiempo que posibilitaba aplicar una política fiscal de detracción de rentas de la ampliada comunidad de contribuyentes que beneficiaría a un amplio espectro social.

Pero esa participación urbana, que se acordaba sobre el pacto político que presidió la reunión de Cortes de 1480, muy pronto se vio desbordada por las posibilidades que ofrecía la intervención de la monarquía, que se situaba en campos de acción estratégicos que hasta entonces habían sido de incumbencia urbana. En contrapartida, las ciudades ampliaron las demarcaciones territoriales de su influencia, al convertirse en cabeza de provincias fiscales o sedes de corregimiento regio, por no mencionar a las que contaron con la presencia de la Chancillería o el Consejo como fueron Valladolid, Ciudad Real o Granada. Los cambios vinieron justificados más por las necesidades derivadas de una sociedad y una economía en profunda transformación, que se adaptaba a las nuevas formas de gobierno, dando como resultado la construcción de un nuevo marco de diálogo político, que ya contemplaba la relación rey-súbdito como base del gobierno del reino y llamado a perdurar en la monarquía autoritaria del Antiguo Régimen.

Fecha de recepción del artículo: septiembre 2007.

Fecha de aceptación y versión final: enero 2009. 